Hans Flaatten

Maité Garrouste-Orgeas

\section{The very old ICU patient: a never-ending story}

Received: 25 August 2015

Accepted: 1 September 2015

Published online: 11 September 2015

(C) Springer-Verlag Berlin Heidelberg and ESICM 2015

H. Flaatten $(\bowtie)$

Department of Clinical Medicine, General ICU, Haukeland University Hospital, Bergen, Norway e-mail: hans.flaatten@kir.uib.no

M. Garrouste-Orgeas

Intensive Care Unit, Groupe Hospitalier Paris Saint Joseph, Paris, France

For decades, intensivists have been concerned about the fate of very old ICU patients [1], and one of the first systematic prospective follow-ups in such a group was published in this journal in 1991 [2]. In that study, conducted in 1985, 295 patients above 70 years old were followed for 1 year after discharge. The ICU and 1-year mortality were 26.7 and $64.1 \%$, respectively, but with significantly higher mortality in patients 80 years and above. Most survivors reported a good functional status at home. Since then, a number of original papers on the topic have been published, followed by editorials and reviews [3-5].

The case-mix and intensive care treatment of very old patients, as well as definitions of what is considered old and very old, has obviously changed during these 30 years [6]. Today, few would probably consider 65 years as particularly old. This makes comparisons with previous results difficult to interpret. Still, important questions remain:

- Should we offer very old patients intensive care?
- Does intensive care in this population really make a difference?

- What is the quality of life in those who survive to hospital discharge and beyond?

The forecasted increase in the elderly population in most countries is a more serious concern today than just 20-30 years ago. The proportion of the world's population above 60 years increased from $8 \%$ in 1950 to $12 \%$ in 2013. It will increase more rapidly in the next four decades to reach $21 \%$ in 2050 , and with a relatively larger increase in those above 70 and 80 years [7].

This will, of course, be of particular concern for our ICUs, in which the number of very old patients is already high, and has been estimated to rise considerably [8].

In order to prepare for what to expect in the next decades, we should increase our effort to acquire a broader and better picture regarding present practice and outcomes of very old critically ill patients. At present, most European studies have been performed in France, the Netherlands or the Scandinavian countries. In this issue of ICM, additional results are published from a Canadian multicentre study of 1671 ICU patients above 80 years [9]. In this well-planned and conducted study, one-third of their patients died while in hospital, and half were alive after 12 months. Only $25 \%$ of these survivors reached their pre-ICU physical function. The authors in a previous publication raised the question about the use of critical care resources at the end of life for the very elderly [10].

The impact of age on survival after intensive care has been known for a long time. Both APACHE and SAPS mortality prediction scores lay considerable weight on advanced age. In SAPS-3, the highest number of points in any area is given for age $\geq 80$ years. In the Canadian study, the published APACHE 2 score in their very old patients corresponded well with their reported hospital mortality of $35 \%$. Of more concern is doubtless the continuous high mortality after hospital discharge. 
Figure 1 illustrates the results from 12 outcome studies published after year 2000 in ICU patients above 80 years. The figure clearly demonstrate that 1- to 2-year mortality is frequently increased by $50 \%$ or more following hospital discharge. At present, we have no clear understanding of why this large increase in mortality occurs. Some possible explanations are of course the effects of co-morbidity, but long-term consequences of severe organ dysfunction during the ICU stay could also play a role.

The present study adds to our collective understanding of the impact of critical illness in patients 80 years and older, in particular with regards to their detailed nonmortality outcomes. One problem remains, the individual studies often use different methods to describe morbidity, making comparison between different cohorts difficult. Even mortality, considered to be a very robust outcome, can be used in many ways, and in particular hospital mortality is prone to errors [11]. In the Canadian study, patients with a ICU length of stay $<24 \mathrm{~h}$ were excluded from the study. This means patients dying within the first ICU day are not counted. In a recent study from three Scandinavian ICU registries, the median time to death for patients of 80 years and above was $<24 \mathrm{~h} \mathrm{[12].} \mathrm{To}$ exclude this time-frame from the analysis could have a large impact on reported ICU mortality, and again makes comparisons with other studies difficult.
What are the specific challenges for intensive care research in the very old for the coming years? Some important general research issues in the elderly ICU population have previously been proposed, but not specifically for the very old [13]. Another interesting advance is the potential benefit of a systematic collaboration between intensivists and geriatricians. Frequently, the very old have complex comorbidities important for ICU treatment as well as for post-ICU care. In the postoperative care of hip fractures in the elderly, the inclusion of orthogeriatric care has been shown to reduce hospital as well as 6-month mortality $[14,15]$.

We also need more epidemiological data.

- First, it is still important to conduct prospective followup studies in this group of ICU patients, preferably using a multicentre/multinational approach, with the focus on mortality as well as non-mortality outcomes. The present Canadian study can serve as a good example of how this can be set up. As a supplement, national ICU registries can also be a source of more knowledge, as exemplified by Denmark [16], where the 30 -days and 12-month mortality rate in a large group of very old ICU patients ( 80 and above) were found to be very similar to the Canadian study.

- Second, we should agree on common outcomes and their definitions, in particular for the various non-

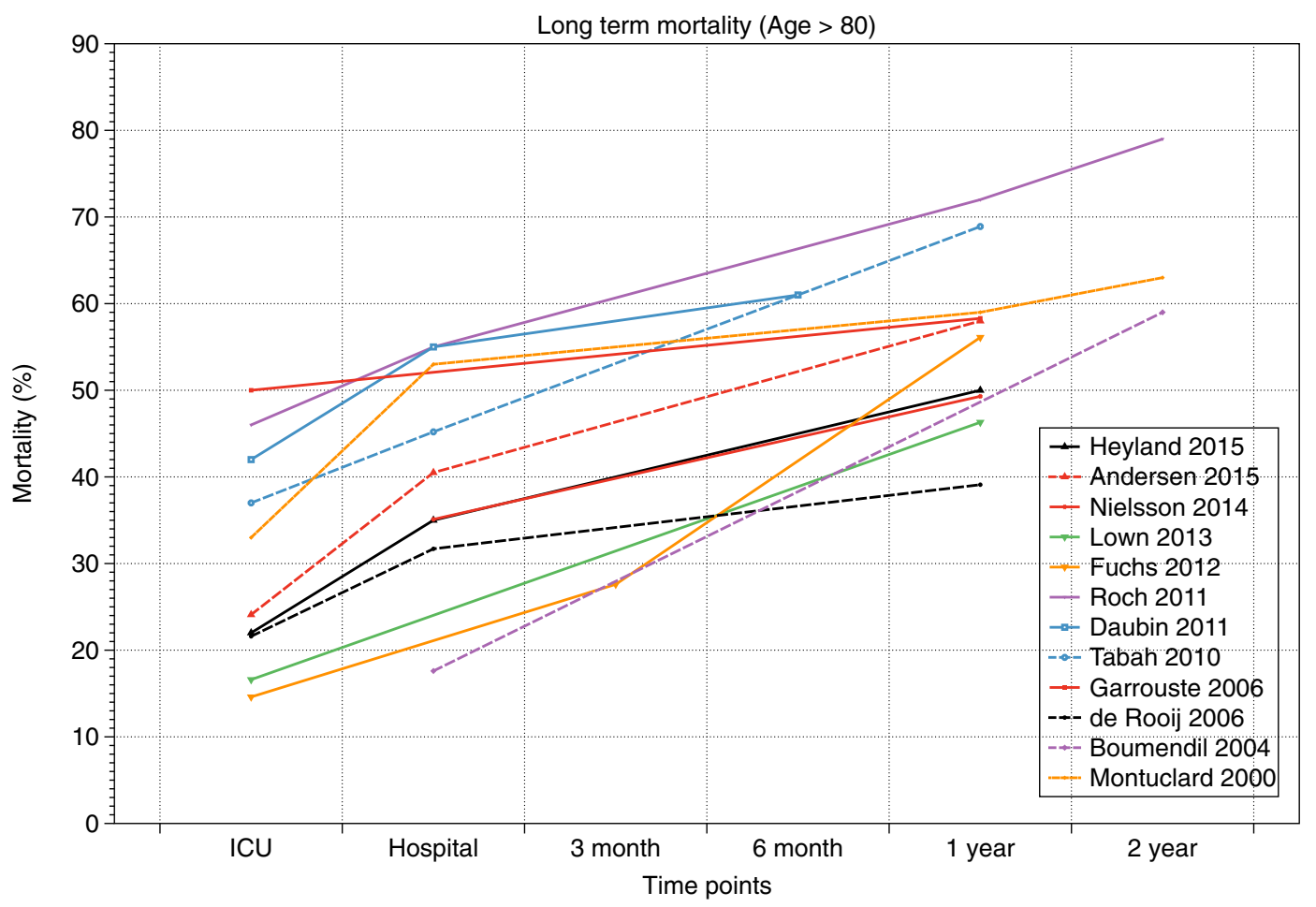

Fig. 1 Mortality rates at different time-points up to 2 years in 12 published studies on outcome in non-selected ICU patients 80 years and above (publications from year 2000 until now) 
mortality outcomes, including similar tools for research. In this connection, we must increase our knowledge about attitudes and values in the very old population with regards to care, life-sustaining therapies and end-of-life problems related to critical illness. In particular, elderly survivors after intensive care may have important messages for us.

- Third, we should expand our knowledge about the causes of death after hospital discharge in this particular group. This could later become an area for studies on how to hopefully avoid some of the late deaths.

- And lastly, we should perform research to find better tools for outcome prediction in very old patients at the earliest time during their ICU stay. This is particularly important in order to avoid prolonged suffering in patients who eventually will die in the hospital, with increased cost for patients, relatives and society.

\section{References}

1. Champion EW, Mulley AG, Goldstein MA, Barnett O, Thibault GE (1981) Medical intensive care for the elderly. JAMA 246:2052-2056

2. Mahul P, Perrot D, Tempelhoff G, Gaussorgues P, Jospe R, Ducreux JC et al (1991) Short- and long-term prognosis, functional outcome following ICU for elderly. Intensive Care Med 17:7-10

3. Flaatten $H$ (2007) Intensive care in the very old: are we prepared? Acta Anaesthesiol Scand 51:519-521

4. Boumendil A, Somme D, GarrousteOrgeas M, Guidet B (2007) Should elderly patients be admitted to the intensive care unit? Intensive Care Med 33:1252-1262

5. Nguyen Y-L, Angus DC, Boumendil A, Guidet B (2011) The challenge of admitting the very elderly to intensive care. Ann Intensive Care 1:29

6. Lerolle N, Trinquart L, Bornstain C, Tadié J-M, Imbert A, Diehl J-L et al (2010) Increased intensity of treatment and decreased mortality in elderly patients in an intensive care unit over a decade. Crit Care Med 38:59-64

7. United Nations, Department of Economic and Social Affairs, Population Division (2013) World Population Ageing 2013. ST/ESA/ SER.A/348. http://www.un.org/ en/development/desa/population/ publications/ageing/WorldPopulation Ageing2013.shtml. Accessed 25 Aug 2015
8. Laake JH, Dybwik K, Flaatten HK, Fonneland I-L, Kvåle R, Strand K (2010) Impact of the post-World War II generation on intensive care needs in Norway. Acta Anaesthesiol Scand. 54:479-484

9. Heyland D, Garland A, Bagshaw S, Cook D, Rockwood K, Stelfox H et al (2015) Recovery to baseline physical function after critical illness among patients aged 80 years or older: a multicentre prospective observational cohort study. Intensive Care Med 41

10. Heyland D, Cook D, Bagshaw SM, Garland A, Stelfox HT, Mehta S et al (2015) The very elderly admitted to ICU: a quality finish? Crit Care Med 43(7):1352-1360

11. Rydenfelt K, Engerström L, Walther S, Sjøberg F, Strömberg U, Samuelsson C (2015) In-hospital vs. 30-day mortality in the critically ill-a 2-year Swedish intensive care cohort analysis. Acta Anaesthesiol Scand 59:846-858

12. Strand K, Walther SM, Reinikainen M, Ala-Kokko TI, Nolin T, Martner J et al (2010) Variations in the length of stay of intensive care unit nonsurvivors in three Scandinavian countries. Crit Care 14:R175

13. Milbrandt EB, Eldadah B, Nayfield S, Hadley E, Angus DC (2010) Toward an integrated research agenda for critical illness in aging. Am J Respir Crit Care Med 182:995-1003
14. Grigoryan KV, Javedan H, Rudolph JL (2014) Orthogeriatric care models and outcomes in hip fracture patients: a systematic review and meta-analysis. J Orthop Trauma 28:e49-e55

15. Boddaert J, Cohen-Bittan J, Khiami F, Le Manach Y, Raux M, Beinis J-Y et al (2014) Postoperative admission to a dedicated geriatric unit decreases mortality in elderly patients with hip fracture. PLoS ONE 9:e83795

16. Nielsson MS, Christiansen CF, Johansen MB, Rasmussen BS, Tønnesen E, Nørgaard M (2014) Mortality in elderly ICU patients: a cohort study. Acta Anaesthesiol Scand 58:19-26 